\title{
Resenha: Ser criança no exílio e na terra da Esperança
}

Obra: PRESTES, Andréia. Lila em Moçambique. Editora Quase oito. 2020. 40p. Ilustrações Camilo Martins. ISBN 9786580550159.

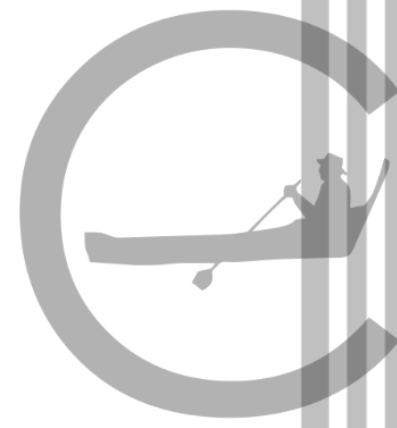

\section{Patrícia Teixeira Santos *}

A obra, que tenho o prazer de resenhar, "Lila em Moçambique", de Andréia Prestes, com ilustrações de Camilo Martins, foi publicada em maio de 2020, com prefácio de Renato Nogueira, agradecimentos à escritora Sonia Rosa, a poetisa Maria Santiago e a professora Sandra Portugal, aos familiares e amigos que a motivaram trazer essa experiência de sua infância e de seus irmãos, filhos do casal Rosa e João Massena. A trajetória da família da autora que passou pela experiência do exílio, primeiro em Moscou, depois em Moçambique, tornou-se inspiração para essa obra que iremos conhecer um pouco melhor.

A autora vai narrar a história de Lila, a irmã mais velha, a quem ela dedica a obra (juntamente com seus filhos João e Rita), em sua busca em contar as memórias da infância.

Esse aspecto na trajetória de Andréia Prestes é ao mesmo tempo bonito e forte. Em seu processo de escrita literária ela se dedicou também a fazer palestras em diversas lives e até fez em uma conferência numa atividade que coordenei na UNIFESP, o minicurso intitulado "trajetórias de vidas africanas e brasileiras". Ela nos trouxe seu propósito de contar, para as crianças, a experiência do exílio, como traduzir tal marco de sua memória em possibilidade da escrita de uma história infantil, ou seja, uma narrativa em que as crianças pudessem entender a experiência em que ela e seus irmãos viveram e, ao mesmo tempo percorrer com eles o imaginário infantil, a beleza, o frescor, os aromas e as pequenas e grandes alegrias de descobrir um ambiente completamente novo, Moçambique durante os anos 80.

\footnotetext{
* Professora de História da África do Departamento de História da Universidade Federal de São Paulo. Pesquisadora colaboradora do Centro de Investigação Transdisciplinar "Cultura, Espaço e Memória" (CITCEM- Universidade do Porto).
} 
A proposta que Andréia Prestes desenvolve, neste texto, faz uma aproximação muito bonita entre sua experiência, que parte de uma família exilada que lutava por liberdade, e a terra de Moçambique, que também lutava por liberdade. A aproximação entre uma família à uma terra, ambas em busca de um mesmo propósito, permitiu que essas crianças pudessem vivenciar um mundo muito rico, que se transformava, de terem um convívio intenso com as crianças do país africano e de observarem os problemas compartilhados entre os adultos brasileiros e moçambicanos, que eram amigos.

Nessas aproximações, a história de Andréia, de Lila e de seus irmãos, se constróem. São crianças que cresceram em meio à diversidade, em diferentes países, vivenciando diferentes histórias, construindo uma rica trajetória de vida que, no início foi marcada por um processo de exílio e sofrimento, e depois se torna o maior patrimônio e riqueza dessa história de vida de Andréia e seus familiares.

Andréia é historiadora, com mestrado em história comparada na UFRJ, doutorado em andamento no Programa de Pós Graduação em Educação da UNIRIO e, por estar fazendo esse percurso, em função dos filhos e da vida que continua, se propõe a transformar uma história muito cara de seu passado em um caminho lindíssimo de poesia, de experiência, de redescoberta, de construção afetiva, intelectual e pessoal. Um processo identitário extremamente belo, em que hora ela apresenta sua vivência em Moçambique, outra ela se sente como se estivesse no Brasil e, no fim, é um coração que pertence a esses dois mundos, que nutriu nela a esperança de dias melhores, de transformações e possibilidades de novos horizontes.

Apresentar esse livro de literatura infantil em uma revista de história é de extrema importância uma vez que apresenta as muitas possibilidades de refletir sobre o exílio, ao mesmo tempo em que denuncia nossa carência de ouvir e conhecer as narrativas feitas por aqueles que cresceram dentro dessa experiência, fazendo suas interpretações do que é ser uma criança exilada.

Andrea Prestes se dedicou também a uma outra obra muito bonita chamada "Minha Valente Avó"1, em que ela faz a homenagem a vovó Maria, viúva de Luiz Carlos Prestes e de quanto que essa avó foi importante, daqui do Brasil, ao enviar para sua família em exílio lembranças do Brasil, doces, aromas, gibis, presentes, brinquedos, que tornaram

\footnotetext{
${ }^{1}$ PRESTES, Andréia, PRESTES, Eduardo, PRESTES, Ana. Minha Valente Avó: Uma homenagem à Maria Prestes. Editora Quase Oito. 2020.
} 
esses momentos extremamente especiais na infância e no convívio da Andréia e dos Irmãos e com os demais exilados brasileiros e cooperantes que se encontravam em Moçambique.

A obra "Lila em Moçambique" e é um convite a nós historiadores ampliarmos possibilidades e linguagens para divulgação científica, criação artística e literária e para um diálogo mais amplo com a sociedade brasileira.

Nos tempos que correm, retratar sobre a experiência de adultos e suas crianças que se deslocam entre fronteiras é de extrema importância. As marcas de rejeição, as possibilidades de integração e os mundo que uma criança pode descobrir sozinha, a partir dos espaços da brincadeira, da escola e nas suas relações, faz parte de um universo ainda por descortinar e precisamos enxergar com bastante cuidado, do ponto de vista da historiografia e da produção da memória social da infância.

Para o ensino de história a obra de Andréia Prestes é de um imenso valor, uma vez que permite trazermos uma outra forma de trabalhar em sala de aula, ou seja, com uma narrativa literária que coloca a experiência infantil como protagonista das relações e possibilidades de interpretação, de experiências de exílio, de uma ditadura e de uma terra que buscava uma liberdade política nos conflitos pós fim do colonialismo. É portanto um relato testemunho de grande riqueza que, através dessa linguagem, nos permite abrir novos horizontes para uma compreensão das subjetividades de outros atores sociais participantes da nossa história recente, como as crianças e adolescentes.

A obra de Andréia Prestes nos traz também um tema muito importante de reflexão, a questão do refúgio, não foi necessariamente o contexto em que seus familiares viveram mas é algo que percebe-se em nossa realidade cotidiana, o deslocamento de famílias inteiras vindas de outros continentes e dentro da própria América Latina em direção ao Brasil, em busca de condição mínima de vida e integridade, mesmo em contexto de pandemia.

Isso nos faz analisar sobre o necessário engajamento social para que essas famílias e sobretudo as crianças, que acompanham esses adultos, possam ser acolhidas e recebidas em dignidade. A partir desse momento de chegada, construir-se de fato políticas públicas para que essas crianças e seus patrimônios culturais sejam respeitados e valorizados, e possam dialogar com a história social das crianças brasileiras. 
Uma nação que se abre para o acolhimento e para a mudança continua sempre saudável e em condições de lidar com embates, diversidades de ideias e de caminhos, ou seja, fazer uma estrada mais democrática. Esse aspecto é fundamental para o Brasil e para o mundo contemporâneo.

A leitura dessa bonita obra nos faz pensar na experiência infantil como algo que passa por uma compreensão da diversidade de uma maneira muito mais ampla e generosa, que é favorecida pelo contexto de encontro, brincadeiras, celebração, de estar juntos e partilhar línguas e saberes. A experiência de Lila e seus irmãozinhos nos lembra o quanto é necessário dar oportunidades às nossas crianças para perceber as diversas estéticas e as diferenças humanas como algo que nos enriquece, nos enobrece, favorece a vida ser mais plena e mais alegre.

O olhar sobre a trajetória necessariamente passa por uma grande questão do presente e Andréia Prestes nos dá essa riqueza em sua obra. Quando à elaboração desse passado ocorre em função do questionamento da escrita de uma narrativa que buscou alcançar os mais jovens, a experiência do exílio, de fazer esse momento parte da história das crianças e da família, em uma forma que essa memória fizesse sentido e trouxesse uma grande riqueza reflexiva, de valorização e de estima do próprio percurso familiar, como oportunidades de aprofundamento e transformação dos laços familiares, promover união e compreensão e, com isso, uma abertura maior para a compreensão do mundo.

Moçambique nesse exato momento atravessa por uma difícil momento de acirrados conflitos no norte do país, com milhares de vítimas e tal fato traz tristes lembranças do períodos de outras guerras e sofrimentos já passados. A história de Lila e da sua infância em Moçambique, traz um alento e faz-se necessário evocar que a vida é algo muito mais rico e complexo e isso ajuda a atravessar processos políticos desagregadores.

Seja muito bem vinda essa linda obra a e que possamos ser premiados com mais e mais lindas histórias da querida autora Andréia Prestes.

\section{REFERÊNCIAS BIBLIOGRÁFICAS}

BOURDIEU, Pierre. A ilusão biográfica, IN: FERREIRA, Marieta de Moraes e AMADO, Janaína(org,). Usos e abusos da história oral. Editora FGV, 2015. 
SANTOS, Patrícia Teixeira. Educação e diversidade: uma análise da trajetória da Escola Industrial de Carapira, Moçambique (1964-1975), IN: PEREIRA, Amilcar Araujo; MONTEIRO, Ana Maria (orgs.). Ensino de História e culturas afro-brasileiras e indígenas: raça e mercado de trabalho. Pallas Editora, 2021, p. 245-264.

POLLAK, Michael. Memória, esquecimento, silêncio. IN: Revista estudos históricos, volume 2, número 3. Rio de Janeiro: FGV. 1989. p. 3-15.

PRESTES, Andréia, PRESTES, Edu, PRESTES, Ana. Minha Valente Avó: Uma homenagem à Maria Prestes. Editora Quase Oito. 2020

VELHO, Gilberto. Memória, identidade e projeto, IN: VELHO, Gilberto. Projeto e metamorfose: antropologia das sociedades complexas. Zahar, 1994.

Colaboração na edição de texto: Tamires Sodré de Paula. 